\title{
"AVANTE, SOLDADOS PERNAMBUCANOS, O MUNDO NOS OBSERVA": A Junta de Goiana e a Convenção de Beberibe no contexto da Independência do Brasil
}

\author{
Flavio José Gomes Cabral*
}

\begin{abstract}
RESUMO: Em 29 de agosto de 1821, várias lideranças políticas e econômicas pernambucanas instalaram uma Junta Governativa Provisória na Vila de Goiana com o objetivo de desestabilizar o governador régio Luís do Rego Barreto e adequar a Província de Pernambuco à nova política inaugurada em 1820 com a Revolução do Porto. Esta decisão foi ratificada pela Convenção de Beberibe e contou com a concordância do governador. Para uma historiografia tradicional desenvolvida pelo Instituto Histórico Geográfico Brasileiro (IHGB), esses acontecimentos foram vistos como separatistas; portanto, não deveriam ser citados, porque prejudicavam os esforços para a consolidação do Estado e da nação. Em resposta a essa indignação, começaram a ser produzidas em Pernambuco obras que apontavam que a província havia, por meios de tais eventos, se tornado independente bem antes do famoso Grito do Ipiranga (1822), o que é um equívoco.

PALAVRAS-CHAVE: Revolução do Porto, Junta de Goiana, Convenção de Beberibe, Independência do Brasil.

\section{"Onward, Pernambuco soldiers, the world is watching us": The Board of Goiana and the Beberibe Convention in the context of the Independence of Brazil}

ABSTRACT: On August 29, 1821, several political and economic leaders in Pernambuco installed in the a Provisional Governing Board in Vila de Goiana in order to destabilize the royal governor Luís do Rego Barreto and adapt the Province of Pernambuco to the new policy inaugurated in 1820 with the Porto Revolution. This decision was ratified by the Beberibe Convention and had the agreement of the governor. For a traditional historiography developed by the Brazilian Geographic Historical Institute (IHGB), these events were seen as separatists; therefore, they should not be mentioned because they undermined the efforts to consolidate the state and the nation. In response to this indignation, studies began to be produced in Pernambuco indicating that the province had, by means of such events, become independent well before the famous Cry of Ipiranga (1822), which is a mistake.

KEYWORDS: Porto Revolution, Junta de Goiana, Beberibe Convention, Independence of Brazil

\section{"Adelante, soldados pernambucanos, el mundo nos observa": La Junta de Goiana y la Convención de Beberibe en el contexto de la Independencia de Brasil}

RESUMEN: El 29 de agosto de 1821, varios líderes políticos y económicos de Pernambuco instalaron en el Pueblo de Goiana una Junta de Gobierno Provisional con el objetivo de desestabilizar al gobernador real Luís do Rego Barreto y adaptar la Provincia de Pernambuco a la nueva política inaugurada en 1820 con la Revolución del Porto. Esta decisión fue ratificada por la Convención de Beberibe y contó con el acuerdo del gobernador. Para una historiografía tradicional desarrollada por el Instituto Histórico Geográfico Brasileño (IHGB), esos eventos fueron vistos como separatistas; por lo tanto, no deberían mencionarse, porque perjudicavan los esfuerzos para consolidar el Estado y la nación. En respuesta a esta indignación, comenzaron a producirse obras en Pernambuco que indicaban que la provincia, por medio de tales eventos, se había logrado su independencia mucho antes del famoso Grito do Ipiranga (1822), lo cual es un error.

PALABRAS CLAVE: Revolución del Porto, Junta de Goiana, Convención de Beberibe, Independencia de Brasil.

\footnotetext{
*Doutor em História pela Universidade Federal de Pernambuco. Atualmente é Profesor Adjunto na Universidade Católica de Pernambuco, vinculado ao Programa de Pós-Graduação em História. Contato: R. do Príncipe, 526 - Boa Vista, CEP: 50050-900, Recife-PE, Brasil. E-mail: gomescabral@uol.com.br. ORCID: https://orcid.org/0000-0001-9174-0378
} 


\section{A revolução vintista e seus desdobramentos em Pernambuco}

Os primeiros anos da década de 1820, período da entrada do Brasil e de Portugal na política moderna, são um período importante para se compreender os diversos caminhos que as elites políticas e intelectuais luso-brasileiras estavam planejando. Se, por um lado, as elites lusitanas procuravam reconquistar a proeminência de Portugal, perdida em 1807 com a fuga da corte para os trópicos, de outro, o Brasil procurava se afirmar enquanto reino no seio do mesmo império. Estas questões iriam dividir opiniões, como escreveu João Paulo Pimenta ${ }^{1}$, e “configurar posições progressivamente antagônicas no jogo que conduziria o Brasil à sua independência de Portugal”. A separação do Brasil do Reino Unido português para a consolidação do Império com a Independência não se deu sem conflitos e derramamentos de sangue, como muito bem observou José Honório em seu clássico "Conciliação e reforma no Brasil",2.

No dia 24 de agosto de 1820 houve um pronunciamento militar na cidade do Porto e, posteriormente, em 15 de setembro em Lisboa, tinha início em Portugal uma revolução liberal destinada a instaurar no Reino Unido um regime constitucional inspirado nos movimentos constitucionais espanhóis irrompidos no primeiro dia do ano de 1820. Insatisfações generalizadas brotavam na velha metrópole, algumas relacionadas à permanência do monarca na América, que causou nos portugueses sentimentos de inferioridade em relação ao Brasil. Acrescentava-se a este quadro a grave e persistente crise produtiva, mercantil e financeira em uma conjuntura bastante desfavorável para Portugal, que remonta ao ano de 1808, por ocasião da abertura dos Portos do Brasil ao comércio internacional ${ }^{3}$. As mudanças desejadas pelos liberais portugueses não pretendiam atacar a monarquia, tampouco a religião católica, conforme explicou o Desembargador Manuel Fernandes Tomás, um dos principais expoentes da revolução portuguesa ${ }^{4}$.

O desembargador também esclarecia: "ninguém será incomodado por suas opiniões". Com isso abria a possibilidade para a liberdade de imprensa e de opinião e fazia cair por terra as punições por crime ideológico ${ }^{5}$. Entre outras exigências da revolução vintista, nome pelo qual ficou conhecida a revolução e a cultura política de 1820, os liberais portugueses, além da Constituição, exigiam o retorno imediato à Lisboa de D. João VI, que se encontrava no Rio de Janeiro desde 1808. O debate sobre o regresso do rei havia começado a tomar vulto em Portugal em 1814; entretanto, o soberano procurou postergar constantemente seu retorno, para desespero dos portugueses ${ }^{6}$. Por ocasião de sua aclamação, ocorrida no Rio em 1818, 
realizou-se cerimônia concorrida, o que de certa forma predizia que a corte portuguesa acabaria americana. Em 1820, a questão foi retomada e, não tendo como fugir e estando praticamente encurralado, o rei decidiu partir e deixar como regente do Reino do Brasil seu lugar-tenente: o príncipe herdeiro, D. Pedro.

Como havia pressa para que a monarquia fosse constitucionalizada, foi necessário que as Cortes fossem convocadas para possibilitar eleições para deputados em todo o reino. Com a instalação das Cortes no dia 26 de janeiro de 1821, reforçava-se que tudo o que se fazia era em nome do monarca ausente e contando com sua aquiescência final ${ }^{7}$. Para o ministro Tomás Antônio Vila Nova Portugal, representante de uma ala conservadora, a convocação de Cortes feita à revelia do rei era ilegal, e ele não via com bons olhos o retorno do soberano para a Europa porque dessa forma se sujeitaria aos revolucionários ${ }^{8}$.

Um dos compromissos dos deputados foi criar um novo governo - a Regência -, que, em nome de D. João VI, passou a exercer o poder executivo até a chegada do monarca. Em 29 de setembro de 1821, as Cortes, contando com a maioria dos deputados lusitanos, uma vez que muitos representantes do Brasil ainda não haviam chegado à Europa, aprovaram a reorganização da forma de governo do Reino do Brasil e da sua administração pública: os governos provinciais ficariam diretamente subordinados à Lisboa, impedindo que se organizasse um governo centralizado no Rio de Janeiro9 . O Soberano Congresso aprovou também o novo código civil e criminal, a concessão da liberdade de imprensa, a abolição de certas práticas penais, a extinção da inquisição e da inconfidência e a anistia aos presos políticos ${ }^{10}$.

Por ocasião da organização da nova administração política, militar e financeira das províncias brasileiras, ficou determinado que as províncias seriam governadas por Juntas Provisórias de Governo, que substituiriam os antigos governadores régios. Esta medida traria sérias consequências em Pernambuco, que, desde 1817, vinha sendo governado pelo CapitãoGeneral Luís do Rego Barreto, defensor da monarquia absoluta. Ele procurou barrar algumas dessas reformas e, enquanto não chegaram deliberações expressas de Lisboa, ele se conservou na governança e causou exasperações.

Segundo o olhar da historiadora portuguesa Maria Cândida Proença ${ }^{11}$, no período em estudo as relações entre Brasil e Portugal foram embaraçadas pelas dificuldades de comunicação já que os países eram separados pelo Atlântico, oceano difícil de ser vencido em pouco tempo. Muitas das deliberações no Rio de Janeiro foram adotadas sem se dispor de 
conhecimentos do que se passava em Lisboa e vice-versa. Para Hipólito da Costa, a revolução portuguesa despertaria no Brasil desejos de imitação "com esperanças de melhoramentos" ", e as notícias deveriam causar grandes rumores. Para o jornalista, o Brasil havia mudado bastante tanto demográfica quanto economicamente e, mesmo assim, a Coroa insistia em administrá-lo como o fazia 300 anos antes. Hipólito da Costa publicava, em janeiro de 1821, que o tempo em que as pessoas pensavam que não existia outro governo "que não fosse o absoluto" havia passado e com certa facilidade obtinham conhecimento do que se passava ao seu redor ${ }^{13}$.

\section{Impasses entre liberais e absolutistas em Pernambuco}

As novidades sobre a Revolução do Porto chegaram a Pernambuco no dia 22 de outubro de 1820. Nesse dia, Luís do Rego Barreto escrevia para o ministro Tomás Antônio de Vila Nova Portugal dando-lhe conta dos problemas pernambucanos e revelando-lhe seu desejo de se viajar até o Povoado de Bonito, que, em medidas atuais, fica a cerca de $130 \mathrm{~km}$ do Recife. Ele queria dissolver uma comunidade sebastianista que, em sua opinião, preparava um movimento contrarrevolucionário em solidariedade à Revolução de $1817^{14}$. O governador desistiu da viagem; depois, com a chegada do paquete inglês Chresterfield vindo da Europa, foi avisado das primeiras notícias sobre a Revolução do Porto ${ }^{15}$. Por um portador, recebeu várias mensagens da parte dos governadores do reino explicando as mudanças políticas naquele país. Luís do Rego imediatamente mandou providenciar cópias daquelas correspondências e as remeteu para a corte carioca juntamente com uma carta dirigida ao ministro Tomás Antônio. Apesar de confiar em seus métodos de coerção, externava medo de que as novidades se propagassem e estimulassem tumulto e rebeldia ${ }^{16}$.

O General Luís do Rego gabava-se da fama de ser temido por seus métodos de truculência. Apesar de tudo isso, ele tinha receio de ser contestado ou, como sugere Balandier $^{17}$, sabia bem que um poder estabelecido sobre a força da violência tem sua existência constantemente ameaçada. Àquela altura, não faltava quem não desejasse se vingar de suas iniquidades por ocasião do desmonte da revolução de 1817. O cônsul norte-americano Joseph Ray, que chegou a Recife naquela ocasião, observou que a população "podia não saber o que era liberdade, mas com certeza aprendera o que era opressão" ${ }^{\prime 18}$. Segundo Oliveira Lima $^{19}$, Luís do Rego era homem culto e inteligente e sabia que não podia se opor por muito tempo às transformações políticas em andamento. Seu tino político até certo ponto era avivado pelas luzes do genro, Rodrigo da Fonseca Magalhães, redator do jornal Aurora 
Pernambucana e secretário do governo, que se tornara seu principal conselheiro e o encorajara a tomar muitas decisões que procuravam adequar as velhas estruturas do Antigo Regime às inovações.

Em 26 de março de 1821, uma embarcação vinda do Rio atracou no porto recifense portando a notícia de que D. João VI havia jurado as Bases da Constituição no dia 26 de fevereiro. Luís do Rego, que permanecia renitente em mudar o sistema de governo provincial, editou uma proclamação explicando a possibilidade de haver mudanças, mas não esclarecia que tipos de mudança deveriam ocorrer. Ele também entendia que, após o juramento do monarca à futura Constituição, as juntas governativas eleitas no Pará e na Bahia, e até mesmo a Junta Provisional do Governo Supremo do Reino formada em Lisboa, poderiam ser $\operatorname{extintas}^{20}$

Em 26 de maio de 1821, os recifenses presenciaram o desembarque do restante dos prisioneiros políticos que se encontravam encarcerados na Bahia, acusados de terem se envolvido na Revolução de 1817. Muito deles eram homens de considerável posição social, alguns inclusive seriam eleitos deputados às Cortes de Lisboa e, posteriormente, como destacou Bernardes ${ }^{21}$, teriam ativa participação no processo da Independência. Vale destacar que toda aquela gente era reintegrada ao convívio social não por clemência do rei, como havia ocorrido em 1818 por ocasião de sua aclamação, mas por determinação da Justiça. Por influência da revolução vintista, o Tribunal da Relação da Bahia libertou os presos após haver anulado os processos que contra eles haviam sido instaurados. Para Luís do Rego, o retorno daqueles homens representava perigo ao absolutista, e seu receio era de que os debates políticos se inflamariam, como de fato se verificou ${ }^{22}$.

\section{Os movimentos liberais de Goiana e a Convenção de Beberibe}

Alguns dos recém-chegados da Bahia tinham em mente desbancar o governador, mas sabiam que dificilmente lograriam sucesso em Recife e seus arredores. Então, estabeleceramse no norte da província, na Vila de Goiana, nas divisas com a Paraíba, onde articularam a resistência contra o general. A escolha daquela vila talvez não tenha sido obra do acaso. Goiana era um dos lugares pernambucanos mais importantes do princípio do século XIX e sua situação geográfica permitia a comunicação com o Recife e o interior, inclusive com a Paraíba, com quem fazia fronteira. Todos esses pontos eram importantes em caso de as lutas se prolongarem por muito tempo. Ao menos a vila poderia, sem grande atropelo, ser abastecida de víveres e outros produtos, uma vez que estava numa das rotas de passagem de 
tropeiros e tangerinos, que transportavam suas reses e outros produtos. Pelo porto fluvial goianense escoavam riquezas, e a vila também se comunicava com o Rio de Janeiro e Lisboa, principais centros do poder $^{23}$.

Uma entre outras medidas tomadas pelo governador na tentativa de mostrar que a província caminhava para sua reforma administrava foi à convocação de um Conselho em 29 de março de 1821, que mais tarde foi transformado em Conselho Consultivo e se conservaria até o momento em que chegassem ordens de Lisboa ordenando que tipo de governo deveria ser estabelecido na província. A atribuição desse colegiado era tomar decisões administrativas e preparar a província para o processo eleitoral para os deputados às Cortes lisboetas. Contudo, ele não conseguia trabalhar, uma vez que entrava em frequente conflito com o governador, que o dissolvia e o substituía por outros que estivessem afinados com suas ideias $^{24}$. As divergências entre os liberais e os absolutistas se tornaram insustentáveis, a ponto de, em julho de 1821, o governador sofrer um atentado na Ponte da Boa Vista, o que o motivou a mandar vários suspeitos para a prisão. Eles foram conduzidos a Lisboa para serem julgados, mas, por falta de provas, a Justiça os libertou ${ }^{25}$.

Quando o governador ainda convalescia de um tiro desferido contra ele na citada ponte, tomou conhecimento das agitações políticas ocorridas na Mata Norte, mais precisamente na Vila de Goiana. Elas foram ganhando corpo com a adesão de vários senhores de engenhos da região. Os grupos se reuniram em várias casas para "por um paradeiro à continuação do estado miserando" ${ }^{26}$ da província, como esbravejava Felipe Mena Calado da Fonseca, antigo escrivão da correição do Ceará e um dos mais aguerridos opositores de Luís do Rego. Durante vários meses e em sigilo, Mena Caldo e Manoel Clemente orquestraram o levante. Para isso, estiveram na Paraíba, onde, longe do alcance do governador paraibano Joaquim Rabelo da Fonseca Rozado, fizeram contatos com velhos companheiros de enxovia para solicitar apoio. Após a anuência de várias lideranças de Nazaré, Paudalho, Limoeiro e Tracunhaém, uma coluna composta de cerca de 600 homens, que posteriormente se engrossaria, seguiu em direção à Goiana ${ }^{27}$. Na tentativa de sensibilizar as tropas, Mena Calado e Manoel Clemente redigiram uma proclamação em que pediam que todos se irmanassem no firme propósito de trabalhar pela regeneração. O manifesto reverberou como grito de guerra: “Avante, Pernambucanos, o mundo nos observa: marchemos entoando o sagrado nome da pátria dos bravos"28. 
A Vila de Goiana foi sitiada na noite do dia 28 de agosto de 1821. Na manhã do dia seguinte, a vila aderiu ao movimento, apesar da oposição do juiz-de-fora e presidente da Câmara, dr. Domingos Salvado da Silva Sarafana, aliado político do general. Imediatamente a Câmara foi ocupada e forçou-se sua anuência. Nesse interregno, foi convocada uma eleição para se instalar uma Junta Provisória, que deveria se submeter apenas "ao senhor rei D. João VI e às Cortes" ${ }^{29}$. Este governo propunha o afastamento de Luís do Rego e a realização de eleições e estava formado por Francisco de Paula Gomes dos Santos (presidente e proprietário de terra), Felipe Mena Calado da Fonseca (secretário), capitão-mor Joaquim Martins da Cunha Souto Maior (capitão-mor de Goiana e senhor do engenho Cangahu), padre Manoel Silvestre de Araújo, Manuel dos Reis Curado (professor de latim em Goiana), Antônio Máximo de Sousa (proprietário do engenho Terra Nova), capitão José Vitorino Delgado de Borba Cavalcanti de Albuquerque (senhor do engenho Palheta) e Bernardo Pereira do Carmo (português, vereador goianense) ${ }^{30}$.

Na visão de Evaldo Cabral, a instalação da Junta de Goiana “insere-se nos quadros do constitucionalismo português e visava garantir a adesão da província ao regime implantado em Portugal a partir da Revolução do Porto"31. Para celebrar sua fundação, verificaram-se em Goiana, no dia 2 de setembro, festas de que tomaram parte as tropas e a população. Uma das deliberações do governo goianense foi a aprovação da proposta que solicitava que o governo do Recife enviasse para aquela Junta todos os documentos a ele dirigidos pelas Cortes e pela regência do Príncipe Pedro, e também foi ordenado à Junta da Real Fazenda que suspendesse o pagamento dos ordenados de Luís do Rego e de pessoas ligadas a ele, "só podendo as despesas públicas ser autorizadas pelo governo verdadeiramente legal”,32.

Quando Luís do Rego tomou conhecimento das ocorrências na Mata Norte, marcou imediatamente uma convocação para uma nova eleição no Recife de um Governo Provisório, denominado Conselho Constitucional Governativo da Província ${ }^{33}$. Na realidade, tal atitude procurava atender as exigências da Junta de Goiana, mas mantendo-se o general no comando do governo. Durante os debates, houve conflitos, uma vez que para os opositores de Luís do Rego, o citado Conselho Constitucional, se inspiravam no modelo das Juntas Provisórias com o objetivo de imprimir legalidade. O jornalista Hipólito da Costa explicou que o conselho não tinha legitimidade, uma vez que não havia sido legalizado pelas Cortes. Na visão do jornalista, os conselheiros foram escolhidos para votar naquilo em que o mandatário provincial mandasse. 
A reação da junta goianense foi rápida. Imediatamente enviou cartas para as câmaras provinciais, ao regente D. Pedro, ao rei e às Cortes, acusando as manobras do general de inconstitucionais e denunciando que o conselho recifense havia sido organizado por ele sem a aquiescência das câmaras provinciais ${ }^{34}$. Com exceção das Câmaras do Cabo, Ipojuca, Sirinhaém e Santo Antão, Luís do Rego não contava com o apoio das demais câmaras provinciais, que inclusive se recusaram a atendê-lo sobre o envio de forças armadas para desbancar os liberais. Em $1^{\circ}$ de setembro de 1821, a Câmara de Limoeiro, localizada no Agreste, ao prestar juramento à Constituição, declarou apoio à Junta de Goiana, sendo seguida por outras. A Câmara de Paudalho, reunida no dia 7 de setembro, não apenas formalizou apoio aos goianenses como tentou convencer os santantenses a abandonar o general ${ }^{35}$.

Como Luís do Rego não dava sinais de deixar o governo, em Goiana ficou acordada a invasão do Recife. Vendo que o governo do Recife não se manifestava, os goianenses resolveram marchar na noite de 21 de setembro em direção àquela vila. A inglesa Maria

Graham $^{36}$, que pouco antes havia chegado ao Recife a bordo da fragata Doris, tornou-se testemunha ocular desses eventos. Segundo ela, homens armados atacaram a Cidade de Olinda, ao norte, e o Povoado de Afogados, ao sul. Durante as refregas, houve derramamento de sangue e perda de vidas. Luís do Rego tentou responder ao ataque mobilizando tropas, mas elas recuaram devido a vários problemas.

\section{O ocaso do governo absoluto do Recife}

No dia 4 de outubro de 1821, em virtude do clima acirrado, uma comissão apresentouse em Beberibe perante as forças de Goiana em nome de Luís do Rego Barreto propondo uma trégua. Tratava-se dos comerciantes Bento José da Costa e Gervásio Pires Ferreira, os tenentes-coronéis Luís Francisco de Paula Cavalcanti de Albuquerque (que viria a ser Visconde de Suassuna) e o coronel João de Araújo Cruz, enviado do governo paraibano. Este havia estado em Goiana com proposições de paz em outro momento, mas elas não foram atendidas.

Após diversas idas e vindas da comissão, um acordo começou a ser traçado. Em 5 de outubro de 1821, algumas lideranças dos dois governos e alguns representantes das câmaras interioranas se reuniram na povoação de Beberibe, sede do governo de Goiana, e assinaram um armistício em que ficaram acertados alguns pontos importantes: “Que se esperariam as Ordens de Sua Majestade e das Cortes para a instalação da Junta Provisória, que deve 
Governar a Província por inteira" ${ }^{37}$. Enquanto isso, Luís do Rego e seu conselho ficariam no governo, restringindo-se, porém, apenas à Vila do Recife e à Cidade de Olinda e seus termos. Estabeleceu-se que a Junta de Goiana continuaria responsável pela administração das vilas interioranas. Tanto o governo do Recife quanto o de Goiana deixariam de existir logo que fosse instalada a Junta Provisória, segundo ordens das Cortes e do soberano. Além disso, os citados governos não deveriam se envolver em questões de opiniões políticas, as estradas e outros meios de comunicação deveriam ser desbloqueados e livres de quaisquer obstáculos e os soldados de ambas as tropas seriam considerados desertores se baldeassem de uma para outra parte.

Antes de ser efetivado, o acordo, que ficou conhecido por Convenção de Beberibe, passou por vários ajustes. Houve vozes discordantes, como a de Felipe Mena Calado da Fonseca, um dos radicais mais exaltados. À medida que as conversas avançaram, ele foi obrigado a ceder em vários pontos, principalmente quando se expuseram os problemas de ordem econômica da província. Era preciso "sossegar o espírito dos povos, e aliviar a agricultura da suspensão dos trabalhos rurais, desembaraçando as milícias empregadas no restabelecimento da ordem" ${ }^{\prime 38}$.

Mesmo depois da Convenção de Beberibe, várias localidades da Mata Sul continuavam resistindo, em apoio ao general. Os enfrentamentos entre Luís do Rego e a Junta de Goiana sinalizavam que não se chegaria a uma solução definitiva. Muitas foram as ações do mandatário para dissolvê-la ou cooptá-la. Em Lisboa, em atendimento as insistentes reclamações dos deputados pernambucanos, resolveu o Soberano Congresso destituir o general por meio do Decreto de $1^{\circ}$ de setembro de 1821 . Com esta decisão, mandava também instalar em Pernambuco sua Junta de Governo. Ela seria de caráter provisório e deveria ser eleita por um colégio eleitoral reunindo as comarcas de Olinda, Recife e do Sertão. O general foi informado dessas decisões por meio de uma carta de D. João VI datada de 2 de setembro de 1821 e que teve ampla divulgação no jornal Segarrega de 1 de dezembro.

Com a exoneração de Barreto, foi dado início ao processo eleitoral para a escolha da Junta Provisório de Pernambuco. As câmaras foram convocadas a enviar representantes, que, reunidos na Sé de Olinda no dia 26 de outubro de 1821, elegeram o novo governo pernambucano. Ele passou a ser constituído pelo comerciante Gervásio Pires Ferreira (presidente), pelo Padre Laurentino Antônio Moreira de Carvalho (secretário), pelo Cônego Manuel Inácio de Carvalho, pelo Coronel Antônio José Vitoriano Borges da Fonseca, por 
Felipe Néri Ferreira, por Joaquim José de Miranda e pelo comerciante Bento José da Costa. Explicou Mena Calado em suas memórias que,

\begin{abstract}
com a instalação do Governo Provisório em Pernambuco segundo as ordens das Cortes Constituintes, terminou a nossa tarefa, que tinha por objeto somente a expulsão de Luís do Rego Barreto e da sua gente aqui colocada pra prorrogar o sistema moribundo, e talvez inaugurar novas artimanhas como devíamos esperar dos acontecimentos havidos ali com os nossos deputados ${ }^{39}$.
\end{abstract}

Apesar de as Cortes terem estabelecido que as eleições deveriam ocorrer em Olinda, capital da província, vozes contrárias, encabeçadas principalmente pelos comerciantes recifenses de origem portuguesa, reclamaram que o pleito deveria acontecer em Recife, alegando que a vila era o principal centro político e econômico pernambucano - uma espécie de "capital de direito". Eles partiam do princípio antigo de que a capital dos reinos portugueses sempre esteve localizada no local da residência do soberano. Neste sentido alegavam que a vila em destaque desde longas datas era a sede administrativa da província porque era ali que residiam os governadores. Nesta briga, em que se percebem velhos ressentimentos que extravasaram durante a Guerra dos Mascates, ganharam os partidários de Olinda, que engrossaram o coro alegando que as eleições para os deputados nela ocorreram e que a cidade era a sede do episcopado provincial ${ }^{40}$.

\title{
5. A tese do pioneirismo pernambucano e a Independência do Brasil
}

Para uma historiografia tradicional e principalmente pernambucana, os eventos de Goiana e de Beberibe foram entendidos como antecipações locais da Independência, o que é um equívoco. O fulcro central dos citados acontecimentos foi desestabilizar o governador régio e adequar a província à política vintista com a eleição de uma Junta Provisória. O motivo que levou os intelectuais pernambucanos a se posicionar sobre o pioneirismo pernambucano na independência talvez seja em resposta a uma produção historiográfica produzida no Rio imperial pelo Instituto Histórico e Geográfico Brasileiro (IHGB), que entendia que a Revolução de 1817 teve cunho separatista. Tais argumentações merecem observações. A revolução não tinha tal aspiração; pelo contrário, havia forte desejo de que as províncias permanecessem unidas formando uma única república separada do Reino Unido português. E, na tentativa de difundir o movimento, representantes do governo revolucionário foram enviados para algumas províncias portando mensagens deste. A maneira como os historiadores ligados ao IHGB interpretaram a Revolução Pernambucana de 1817 e os 
acirramentos políticos ocorridos em Goiana e em Beberibe não serviam de exemplos para a consolidação do Estado e da Nação.

$\mathrm{Na}$ documentação em torno dos acirramentos políticos que culminaram com a fundação da Junta de Goiana e posteriormente na Convenção de Beberibe - atas, proclamações, cartas, etc. - o termo "independência” aparece constantemente. É preciso certo cuidado para entender o sentido da palavra naquele contexto histórico. O dicionarista Morais, citado nos relatos de 1817, explica que independência é "o oposto a dependência. A liberdade de sujeição, de fazer o quer sem autoridade, ou consentimento de outrem"41. A palavra do século XIX não tinha significado de "emancipação", conforme observou Maria de Lourdes Viana Lyra ${ }^{42}$. O termo havia se incorporado à cultura, ou melhor, ao novo vocabulário político inaugurado em 1820. A palavra foi incorporada pelos liberais, como explica Cecília Helena de Salles Oliveira ${ }^{43}$ para contestar o absolutismo monárquico e o despotismo exercidos pelos diversos agentes reais.

A produção historiográfica desenvolvida pelo IAHGB estava comprometida com a institucionalização da monarquia e seguiu a linha de pensamento de Francisco Adolfo de Varnhagen (1816-1878), autor de "História Geral do Brasil" (1854-57), para quem a Revolução de 1817 não deveria sequer ser mencionada e, se tivesse vingado, teria posto em risco a integridade do Brasil e a construção do Império ${ }^{44}$. Por isso, trazer à tona lembranças ou episódios internos anteriores à Independência do Brasil, muitos dos quais mal resolvidos, seria uma temeridade. Em sua "História da Independência do Brasil"45, obra que se conservou inédita até 1919, quando foi descoberta no Itamaraty, Varnhagen culpou os pernambucanos de serem intransigentes e de terem negado qualquer tipo de conciliação proposta por Luís do Rego para evitar cizânias e derramamentos de sangue. Segundo o autor, os pernambucanos preferiram o caluniar e espalharam boatos de que o general era um déspota. João Manoel Pereira da Silva, autor de "História da Fundação do Império Brasileiro" (1865), comungando do pensamento de Varhagen, ajuizou que a Junta de Goiana tinha espírito independentista sobrevindo da Revolução de 1817.

Mais que em nenhuma província lavrava na de Pernambuco o espírito de independência, que se circunscrevia entretanto no território da antiga capitania. Existiam ali elementos latentes produzidos pela revolução de 1817. As ideias livres, e de um governo local e soberano que ela havia derramado, ajuntavam-se despeitos, ódios e desejos de vingança suscitados pelos castigos rigorosos que se haviam aplicado a muitos dos comprometidos ${ }^{46}$. 
Em um momento em que havia preocupação sobre a consolidação do Estado imperial, os antigos distúrbios políticos pernambucanos evidentemente não deveriam vir à tona porque, sendo independentistas, não contribuiriam para a solução do problema. Entretanto, segundo Lúcia Maria Paschoal Guimaraes ${ }^{47}$, além desses entraves, havia outros talvez mais melindrosos, como, por exemplo, explicar a participação de alguns dos fundadores do IHGB naqueles eventos. Para evitar celeumas, muitos documentos comprometedores, inclusive referentes à província de Pernambuco, foram guardados sob sigilo ${ }^{48}$. O citado Instituto foi fundado em 1838 sob o amparo de D. Pedro II e se empenhou na construção da memória nacional. Para seus membros, a independência decorreu de um processo natural, sem ruptura e traumas, e sua produção historiográfica procurou glorificar a colonização portuguesa. Um dos sócios do Instituto Cônego Fernandes Pinheiro dizia que "a ordem natural das coisas exige que as colônias se destaquem das suas metrópoles; assim como os filhos deixam a casa paterna quando emancipados"

Pereira da Costa, em seus "Anais Pernambucanos", não chega a afirmar com todas as letras, como outros intelectuais de seu tempo, que os eventos de goianenses e de Beberibe concorreram para que Pernambuco se emancipasse antes do famoso gesto do príncipe em 1822. Para ele, os acontecimentos foram importantes para que se consolidassem o "patriótico governo de Goiana" e "a santa causa da liberdade que defendia",50. Nilo Pereira, porém, em seu prefácio ao $8^{\circ}$ volume dos Anais, reeditado em 1983, não deixou de tecer elogios à obra. Entretanto, lamentava que o autor dos Anais, ao se referir a outros eventos locais $(1710,1817$ e 1824), quando os pernambucanos pagaram duras penas pelas suas rebeldias, escreveu que "o nosso grande mestre esqueceu a data de 1821, que é a da Convenção de Beberibe, com a qual Pernambuco ficou autônomo onze meses antes da Independência Nacional"51.

Em 1957, o médico e antropólogo Walter Valente publicava o livro "Maria Graham: uma inglesa em Pernambuco nos começos do século XIX" ${ }^{, 52}$. A obra tem como pano de fundo o diário escrito pela inglesa Graham, testemunha ocular dos acirramentos políticos ocorridos naquele ano. Valente também desejava estudar os citados acontecimentos pernambucanos como subsídios para as palestras que proferiria por ocasião das comemorações do centenário do Ginásio Pernambucano. O escritor, seguindo as mesmas interpretações dos escritores, repetiu as mesmas conclusões. A obra seria relançada em 1974, acrescida de transcrições de documentos produzidos tanto por Luís do Rego quanto pela Junta de Goiana, porém recebeu 
novo título, que demonstra sua convicção: "Antecipação de Pernambuco no movimento da independência: testemunho de uma inglesa" ${ }^{\text {"53. }}$.

Nas comemorações do Sesquicentenário da Independência do Brasil, em 1972, resolveu a comissão pernambucana encarregada de celebrar a efeméride editar o opúsculo "A Convenção de Beberibe - o primeiro episódio da Independência do Brasil", de autoria de Luiz Delgado, fruto de discurso do autor no ano anterior na Academia Olindense de Letras e do Instituto Histórico de Olinda, durante as comemorações do Sesquicentenário da Convenção de Beberibe. A obra foi enriquecida com uma cronologia de eventos relacionados aos acontecimentos pernambucanos de 1821 e a transcrição da ata da sessão da Junta de Goiana instalada na povoação de Beberibe em 5 de outubro daquele ano, quando

\begin{abstract}
desse modo, Pernambuco começou a governa-se a si mesmo, quase um ano antes, onze meses, exatamente, antes do brado do Ipiranga. Fê-lo em uma jornada para a qual não aguardou nem, ordens do Rio de Janeiro nem exemplos de qualquer província do país. Fomos pioneiros da Independência tanto na intenção quanto na realização ${ }^{54}$.
\end{abstract}

Seguindo essa mesma linha de pensamento, várias pesquisas foram desenvolvidas, inclusive no âmbito universitário. Mesmo que atualmente haja maneiras de pesar que diferem das citadas, isso não desmerece os trabalhos aqui elencados; pelo contrário, eles fornecem informações importantes, que ajudam a entender o processo de formação do Estado e da Nação com um olhar voltado para as províncias. Barbosa Lima Sobrinho, em seu conhecido "Pernambuco da Independência à Confederação do Equador", publicado primeiramente em 1979 e em segunda edição em 1998, revisitou o tema e explorou de forma minuciosa as fontes. Destacou que, no período entre 1817 e 1821, se desencadearam na província pensamentos autonomistas que permitiram atribuir a Pernambuco "o direito de figurar no primeiro capítulo da emancipação nacional como pioneiro e não como caudatário reticente ou hesitante" 55 .

Vale destacar o artigo produzido por Amaro Quintas intitulado "A agitação republicana no Nordeste", que segue o mesmo pensamento das produções anteriores. Foi publicado na "História Geral da Civilização Brasileira", organizada por Sérgio Buarque de Holanda $^{56}$. Em 1988, Teobaldo Machado defendeu na UFPE a dissertação “As insurreições liberais em Goiana", posteriormente publicada pela Fundarpe ${ }^{57}$. Amparada em sólida documentação e bibliografia, a pesquisa aborda a disseminação das ideias liberais no interior de Pernambuco no limiar do século XIX, em particular em Goiana. Durante os distúrbios 
políticos ali ocorridos em 1821, atuaram, além da aristocracia rural, setores dos grupos excluídos. A pesquisa ratificou as conclusões dos autores anteriormente citados e admitiu que a "revolução de Goiana" foi um marco "decisivo para a independência do Brasil do jugo português e, ao mesmo tempo, um golpe definitivo no sistema absolutista" ${ }^{58}$.

\section{Conclusão}

Pelas narrativas de Mena Calado, fica muito claro que as comoções políticas ocorridas em Pernambuco em 1821 tinham como objetivo adequar a província à política vintista iniciada um ano antes em Portugal, que concorreu para desmoronar as estruturas de poder nos moldes do Antigo Regime, legitimando o que até então era enquadrado como crime de lesamajestade. Viveram-se momentos pautados na liberdade, o que abriu espaço para que assuntos do domínio da política deixassem de ser assuntos comentados apenas nas rodas palacianas. Ultrapassando essas fronteiras, eles polarizaram as ruas. Vozes se levantaram em várias partes transformando os "espaços públicos", como sugere Habermas ${ }^{59}$, em um imenso tablado onde diversos setores da população procuraram "encenar", parafraseando Balandier" protestar contra o governante. Utilizaram-se diversos atos, alguns difíceis de ser captados em registros escritos - gritos, cantoria, aplausos e disse me disse -, que, para a historiadora francesa Arlette Farge ${ }^{61}$, são expressões de opinião pública e incomodaram o governante.

Os acontecimentos de 1821, iniciados com a fundação da Junta de Goiana, passando pela Convenção de Beberibe e finalmente a saída do General, foram entendidos por uma historiografia ufanista, em particular pernambucana, como antecipações locais da Independência. Segundo Denis Bernardes, tais pensamentos surgiram "pela reação à historiografia imperial e centralizadora de Cairu, de Varnhagen e de Pereira da Silva, entre outros" . Para esses autores, o Rio de Janeiro e as províncias vizinhas teriam sido os artífices da Independência conduzida pelo Príncipe D. Pedro e outras figuras, como José Bonifácio, o Patriarca da Independência, que tiveram de enfrentar diversos movimentos localistas (provinciais), vistos como anárquicos e separatistas, sobretudo desprovidos de visão nacional $^{63}$.

As agitações de 1821 tiveram como objetivo desestabilizar Luís do Rego, tido como déspota. Em todos esses eventos havia desejo de submissão da província às Cortes, à monarquia bragantina e de conservação do Reino Unido de Portugal, Brasil e Algarves. Esta assertiva se encontra presente em vários discursos, cartas e tratativas. O próprio secretário 
Mena Calado, uma das lideranças liberais mais aguerridas, tinha tal desejo. Maria Graham, ao escutar um de seus pronunciamentos, ficou impressionada, pois lhe fazia lembrar "algumas das mais bem escritas proclamações Carbonárias (sic) da Itália” ${ }^{\text {"64 }}$. Pelo que se percebe, os antigos republicanos de 1817 que estiveram à frente dos acirramentos políticos de 1821, com a fundação do Império em 1822 se tornaram monarquistas constitucionais. E, segundo Berbel:

agiam, ainda buscando a associação de partes distintas por meios de definições legais. Continuavam defendendo sua pátria por meio da res-pública. A defesa das reivindicações locais era prioritária para os pernambucanos, mas eles podiam integrar a nação portuguesa desde que respeitada a autonomia da província, legalmente ${ }^{65}$.

Não resta dúvida de que a Revolução do Porto quebrou os elos entre as partes constituintes do reino, como observou Marcus Carvalho ${ }^{66}$. E, segundo o autor, em cada província houve reações com o objetivo de formar juntas governativas. Aliás, o desejo de autonomia provincial, tão acalentado durante a Revolução de 1817, foi concedido pelas Cortes. O governo local foi de fato exercido durante os anos de 1821 e 1822, o que faz compreender "por que houve gente que preferia a manutenção dessa situação à aventura da independência a qualquer custo, muito menos a reboque da nova corte que se constituía em torno do príncipe regente"

\section{Notas}

${ }^{1}$ PIMENTA, João Paulo Pimenta. A independência do Brasil e a experiência hispano-americana (1808-1822). São Paulo: Hucitec Editora, 2015, p. 234.

${ }^{2}$ RODRIGUES, José Honório. Conciliação e reforma no Brasil. $2^{\mathrm{a}}$ ed. Rio de Janeiro: Nova Fronteira, 1982, p. 41.

${ }^{3}$ PIMENTA, João Paulo Pimenta. A independência do Brasil e a experiência hispano-americana (1808-1822). São Paulo: Hucitec Editora, 2015, p. 358.

${ }^{4}$ TOMÁS, Manuel Fernandes. A Revolução de 1820. $2^{\mathrm{a}}$ ed. Lisboa: Editorial Caminho, 1982, p. 48.

${ }^{5}$ Tanto a liberdade de imprensa quanto a permissão de circulação de impressos foram importantes medidas tomadas pela revolução de 1820 , pois concorreram para pressionar o rei a assinar o decreto de 2 de março de 1821, que suspendia provisoriamente toda e qualquer censura sobre a imprensa em geral. No Brasil, a atividade de imprensa era muito limitada, bem como a publicação e circulação de periódico. O "vintismo", nome pelo qual é conhecida a cultura política de 1820 , permitiu que periódicos fossem fundados por esses brasis, inovando o debate político com o surgimento da imprensa. Sobre o tema, leiam-se: BELBEL, Márcia Regina. A nação como artefato: deputados do Brasil nas cortes portuguesas, 1821-1822. São Paulo: Hucitec, 1999, p. 46-49; CABRAL, Flavio José Gomes. Instabilidades políticas em Pernambuco no tempo da Independência do Brasil (1817-1822), Anos 90, Porto Alegre, v.7, 2020, p. 1-18 Disponível em: https://doi.org/10.22456/1983-201X.90820, acesso em 12.10.2020; MOREL, Marco; MARIANA, M. de Barros. Palavra, imagem e poder: o surgimento da imprensa no Brasil do século XIX. Rio de Janeiro: DP\&A, 2003, pp. 23-24; MOREL, Marco. Da gazeta tradicional aos jornais de opinião: metamorfose da imprensa periódica no Brasil. In: NEVES, Lúcia Maria Bastos P. das (org.). Livros e impressos. Retratos do setecentos e do oitocentos. Rio de Janeiro: Editora da Uerj, 2009, p. 153-184; NEVES, Lúcia Maria Bastos das. Corcundas e constitucionais: a cultura política da Independência (1820-1822). 
Rio de Janeiro: Revan, 2003; LUSTOSA, Isabel. Insultos impressos: a guerra dos jornalistas na Independência (1821-1823). São Paulo: Companhia das Letras, 2000.

${ }^{6}$ VARGUES, Isabel Nobre. O processo de formação do primeiro movimento liberal: a Revolução de 1820. In: TORGAL, Luís dos Reis; ROQUE, João Lourenço. História de Portugal. O Liberalismo. Lisboa: Editorial Estampa, 1998, p. 54.

${ }^{7}$ Quando foram convocadas eleições para deputados das Cortes, não se pensou em incluir os representantes das províncias brasileiras, o que causou indignação no jornalista Hipólito da Costa, grande entusiasta da revolução de 1820. Em seu Correio Braziliense ele insistia na importância da participação da representação do Brasil nas diversas discussões. LUSTOSA, Isabel. O jornalista que imaginou o Brasil: tempo, vida e pensamento de Hipólito da Costa (1774-1823). Campinas: Editora da Unicamp, 2019, p. 204.

${ }^{8}$ E neste contexto de vicissitudes que é publicado em francês um folheto anônimo atribuído a Francisco Cailhé de Geine no Rio de Janeiro sob o título "Le roi et la famille royale de Bragança doivent-ils, dans les circonstances présentes, retourner au Portugal, ou bien rester au Brésil?” (Deverão o rei e a família real de Bragança, nas circunstâncias atuais, voltar para Portugal ou ficar no Brasil?). Biblioteca Nacional (BN), I35,10,011. Este folheto causou grande repercussão tanto no Brasil quanto em Portugal e pugnava pela permanência da família real no Brasil, mostrando as vantagens dessa permanência no país no conjunto dos territórios do Reino Unido. $\mathrm{O}$ autor procurou mostrar essa importância lembrando que o Brasil sem grandes entraves passava perfeitamente sem Portugal, ao contrário deste, que dependia principalmente economicamente do Brasil. ALEXANDRE, Valentim. Os sentidos do império: questão nacional e questão colonial na crise do Antigo Regime português. Porto: Edições Aforamento, 1993, p. 504.

${ }^{9}$ NEVES, Lúcia Maria Bastos Pereira das. Corcundas e constitucionais: cultura e política da Independência (1820-1823). Rio de Janeiro: Revan, 2003, p. 267. Cf. RAFFAELLI, Marcelo. Guerras europeias, revoluções americanas. Europa, Estados Unidos e a independência do Brasil e da América Espanhola. São Paulo: Três Estrelas, 2018, p. 201.

${ }^{10}$ VARGUES, Isabel Nobre. O processo de formação do primeiro movimento liberal: a Revolução de 1820. In: TORGAL, Luís dos Reis; ROQUE, João Lourenço. História de Portugal. O Liberalismo. Lisboa: Editorial Estampa, 1998, p. 54.

${ }^{11}$ PROENÇA, Maria Cândida. A Independência do Brasil: Relações externas portuguesas, 108-1825. Lisboa: Livros Horizontes, 1987, p. 46.

12 COSTA, Hipólito da. Correio Braziliense, ou Armazém Literário. São Paulo: Imprensa Oficial do Estado, 2002, p. 167, v. XXVI.

${ }^{13}$ COSTA, Hipólito da. Correio Braziliense, ou Armazém Literário. São Paulo: Imprensa Oficial do Estado 2002, p. 169, v. XXVI.

${ }^{14}$ Sobre o caso dos sebastianistas que se instalaram na Serra do Rodeador em Bonito, leia-se: CABRAL, Flavio José Gomes. Paraíso terreal: a rebelião sebastianista na Serra do Rodeador. Pernambuco, 1820. São Paulo: Annablume, 2004.

${ }^{15}$ Arquivo Nacional (AN). Fundo Gabinete de D. João VI. BR AN, RIO, U1.0.0.528.

${ }^{16}$ Carta de Luís do Rego para o Ministro Tomás Antônio Vila Nova Portugal, 18 de outubro de 1820. Revista do Instituto Arqueológico, Histórico e Geográfico Pernambucano, p. 156.

${ }^{17}$ BALANDIER, Georges. O poder em cena. Brasília: Editora da Universidade de Brasília, 19080, p. 7.

${ }^{18}$ CARVALHO, Marcus J.M.de. Negros armados por brancos e suas independências no Nordeste (1817-1848). In: In: JANCSÓ, István (org.). Independência: História e historiografia. São Paulo: Hucitec, 2005, p. 882.

${ }^{19}$ LIMA, Manuel de Oliveira. O movimento da Independência: 1821-1822. Belo Horizonte: Itatiaia, 1989, p. 84.

${ }^{20}$ SORGINE, Juliana. Da colônia às Cortes. A formação da Junta Governativa de Goiana e a crise do Antigo Regime português em Pernambuco (1821). 159f. Dissertação (Mestrado em História Social) - Universidade Federal do Rio de Janeiro/IFCS, 2005, p. 67-68.

${ }^{21}$ BERNARDES, Denis Antônio. O patriotismo constitucional: Pernambuco, 1820-1822. São Paulo: Hucitec, 2006, p. 311.

${ }^{22}$ BARRETO, Luiz do Rego. Memória justificativa sobre a conducta do marechal de campo Luiz do Rego Barreto durante o tempo em que foi governador de Pernambuco, e presidente da junta constitucional do governo da mesma província. Lisboa: Typografia de Desiderio Marques Leão, 1822, p. 110.

${ }^{23}$ MACHADO, Teobaldo. As insurreições liberais em Goiana. Recife: Fundarpe, 1990, p. 33-34.

${ }^{24}$ CABRAL, Flavio José Gomes. Conversas reservadas: "vozes públicas", conflitos políticos e rebeliões em Pernambuco no tempo da Independência do Brasil. Rio de Janeiro: Arquivo Nacional, 2013, p. 135.

${ }^{25}$ Relator Verdadeiro, 10.1.1822.

${ }^{26}$ FONSECA, Felipe Mena Calado da. Movimento Revolucionário de Goyanna em 1817(sic). Pernambuco: Typografia Mercantil,1873. Revista do Instituto Archeologico e Geographico Pernambucano, vol XIII, n. 71-74, 1908., 5-69, p.13. Disponível em: 〈http://www.dominiopublico.gov.br/download/texto/jn001347.pdf> Acesso 
em 28.11.2020. Em 1873, Mena Calado escreveu um opúsculo intitulado "Movimento revolucionário de Goianna em 1817 (sic), em Pernambuco", editado pela Typographia Mercantil sobre os acontecimentos políticos ocorridos em 1821 em Pernambuco, ao lado do amigo Manoel Clemente de Albuquerque. Devido às inúmeras incorreções, mandou destruir toda a edição. Posteriormente, segundo Alfredo de Carvalho, os ditos relatos foram publicados anonimamente na Revista do Instituto Arqueológico, mas, pelo prólogo e pelo conteúdo, trata-se de uma obra do citado autor. FONSECA, Felipe Mena Calado da. Movimento Revolucionário de Goyanna em 1817(sic). Pernambuco: Typografia Mercantil,1873. Revista do Instituto Archeologico e Geographico Pernambucano, vol. XIII, n. 71-74, 1908, 5-69, p.6. Disponível em: Disponível em <http://www.dominiopublico.gov.br/download/texto/jn001347.pdf> Acesso em 28.11.2020.

${ }^{27}$ Entre os grandes proprietários que se envolveram no movimento contra Luís do Rego, citam-se Manoel Inácio Bezerra de Melo (senhor do Engenho Tamataúpe), dr. Francisco de Paula Gomes dos Santos, Antônio Máximo de Sousa, Manoel Silvestre de Araújo, João Carlos de Melo Albuquerque, José Camelo Pessoa de Melo, padre Manoel dos Reis Curado, Bernardo Pereira do Carmo, capitão José Vitoriano Delgado de Borba Cavalcanti de Albuquerque e capitão José Joaquim Coelho Lopes de Castro. ANDRADE, Manuel Correia de. Movimentos nativistas em Pernambuco. Setembrizada e novembrada. Recife: Universidade Federal, 1971, p. 28-29.

${ }^{28}$ FONSECA, Felipe Mena Calado da. Movimento Revolucionário de Goyanna em 1817(sic). Pernambuco: Typografia Mercantil,1873. Revista do Instituto Archeologico e Geographico Pernambucano, vol XIII, n. 71-74, 1908., 5-69, p.12. Disponível em: Disponível em <http://www.dominiopublico.gov.br/download/texto/jn001347.pdf> Acesso em 28.11.2020.

${ }^{29}$ IAHGP (Instituto Arqueológico, Histórico, Geográfico Pernambucano). Cópias dos ofícios expedidos pelo governo revolucionário [de Goiana], Gaveta 2 - Revolução de 1821, fl. 2. Apeje. OC. Cód. 1, fl. 335.

30 CABRAL, Flavio José Gomes. Conversas reservadas: "vozes públicas”, conflitos políticos e rebeliões em Pernambuco no tempo da Independência do Brasil. Rio de Janeiro: Arquivo Nacional, 2013, p. 155.

${ }^{31}$ MELLO, Evaldo Cabral de. A outra independência: O federalismo pernambucano de 1817 a 1824. São Paulo: Editora 34, 2004, p. 68-70.

${ }^{32}$ LIMA, Manuel de Oliveira. O movimento da Independência: 1821-1822. Belo Horizonte: Itatiaia, 1989, p. 91.

${ }^{33}$ IAHGP. Resumo dos sucessos de Pernambuco, fl. 1v. Coleção Mário Mello, Gaveta 10.

${ }^{34}$ IAHGP. Registro de ofícios, com as devidas cópias, do governo revolucionário de Goiana, 1821, Coleção Mário Mello, Gaveta 2, Revolução de 1821, fl. 14.

35 ARAGÃO, José. História da Vitória de Santo Antão (1626-1843). 2 ed. Recife: Fiam/Centro de Estudos de História Municipal, 1983, p. 133.

${ }^{36}$ GRAHAM, Maria. Diário de uma viagem ao Brasil. In: VALENTE, Waldemar. Maria Graham: uma inglesa em Pernambuco nos começos do século XIX. Recife: Imprensa Oficial, 1957, p. 96, 102.

${ }^{37}$ Resumo do Tratado celebrado entre este Governo [de Goiana], o Conselho Governativo do Recife - assinado em 6 de outubro de 1821. In: PERNAMBUCO. Pernambuco no movimento da Independência (Correspondência oficial do Governo da Província, entre agosto e outubro de 1821). Recife: Conselho Estadual de Cultura, 1973, p. 144-146.

${ }^{38}$ FONSECA, Felipe Mena Calado da. Movimento Revolucionário de Goyanna em 1817(sic). Pernambuco: Typografia Mercantil,1873. Revista do Instituto Archeologico e Geographico Pernambucano, vol XIII, n. 71-74, 1908., 5-69, p. 25-26. Disponível em: Disponível em <http://www.dominiopublico.gov.br/download/texto/jn001347.pdf> Acesso em 28.11.2020.

${ }^{39}$ FONSECA, Felipe Mena Calado da. Movimento Revolucionário de Goyanna em 1817(sic). Pernambuco: Typografia Mercantil,1873. Revista do Instituto Archeologico e Geographico Pernambucano, vol XIII, n. 32, 1908., 5-69, $\quad$ p. $32 . \quad$ Disponível em: Disponível em <http://www.dominiopublico.gov.br/download/texto/jn001347.pdf> Acesso em 28.11.2020

${ }^{40}$ CABRAL, Flavio José Gomes. Conversas reservadas: “vozes públicas”, conflitos políticos e rebeliões em Pernambuco no tempo da Independência do Brasil. Rio de Janeiro: Arquivo Nacional, 2013, p. 168.

${ }^{41}$ SILVA, Antonio de Morais. Bluteau, Rafael. Diccionario da lingua portugueza composto pelo padre D. Rafael Bluteau, reformado, e accrescentado por Antonio de Moraes Silva natural do Rio de Janeiro. 1. ed. Lisboa, Simão Tadeu Ferreira, [1789], p. 149.

${ }^{42}$ LYRA, Maria de Lourdes Viana. A utopia do poderoso império. Rio de Janeiro: Sette Letras, 1994.

${ }^{43}$ OLIVEIRA, Cecília Helena de Salles. Independência e revolução: temas da política, da História e da cultura visual, Almanak, n. $25, \quad 2020, \quad$ p. $\quad 1-52$. Disponível: <https://periodicos.unifesp.br/index.php/alm/article/view/10509/8065> acesso em 01.07.2021.

${ }^{44}$ VARNHAGEN, Francisco Adolfo de. História Geral do Brasil. Rio de Janeiro: Casa H. Laemmert, 1857, p. 374. 
${ }^{45}$ VARNHAGEN, Francisco Adolfo de. História da Independência do Brasil até ao reconhecimento pela antiga metrópole, compreendendo, separadamente a dos sucessos ocorridos em algumas províncias até essa data. Rio de Janeiro: IHGB, [1919].

${ }^{46}$ SILVA, J. M. Pereira da. História da fundação do império brasileiro. Rio de Janeiro: B.L. Garnier Editor, 1865 , p. 96, v.5.

${ }^{47}$ GUIMARÃES, Lúcia Maria Paschoal. Entre a monarquia e a república: a Revolução Pernambucana de 1817 e suas representações no Instituto Histórico e Geográfico Brasileiro. In LESSA, Mônica; FONSECA, Sílvia Carla Pereira de Brito. Entre a monarquia e a república: imprensa, pensamento político e historiografia (1822-1889). Rio de Janeiro: 2008, p. 153.

${ }^{48}$ Entre outros documentos, destacamos uma carta do Governador Caetano Pinto de Miranda Montenegro, que foi expulso de Pernambuco durante a Revolução de 1817, ao Conde da Barca, ofertada em 1839 ao IHGB pelo General José Inácio de Abreu e Lima, filho padre Roma, que foi executado a mando do Conde dos Arcos devido à sua atuação na citada revolução. Mesmo tendo sido considerado um documento de grande importância, decidiu-se que ele não deveria ser publicado na revista do Instituto porque poderia comprometer muitas pessoas ainda vivas. GUIMARÃES, Lúcia Maria Paschoal. Entre a monarquia e a república: a Revolução Pernambucana de 1817 e suas representações no Instituto Histórico e Geográfico Brasileiro. In LESSA, Mônica; FONSECA, Sílvia Carla Pereira de Brito. Entre a monarquia e a república: imprensa, pensamento político e historiografia (1822-1889). Rio de Janeiro: 2008, p. 153; MALEVAL, Isadora Tavares. O Instituto Histórico e Geográfico Brasileiro como preparador da história (1850-1889), História Unisinos, v 24, nº 1, 2020, p. 48.

${ }^{49}$ GUIMARÃES, Lúcia Maria Paschoal. Entre a monarquia e a república: A Revolução Pernambucana de 1817 e suas representações no Instituto Histórico e Geográfico Brasileiro. In LESSA, Mônica Leite; FONSECA, Sílvia Carla Pereira de Brito. Entre a monarquia e a república. Imprensa, pensamento político e historiografia (1822-1889). Rio de Janeiro: EdUERJ, 2008, p. 154-155

${ }^{50}$ COSTA, F.A. Pereira da. Anais pernambucanos. $2^{\text {a }}$ ed. Recife: FUNDARPE, 1984, p. 134, v. 8.

${ }^{51}$ PEREIRA, Nilo. Prefácio. In COSTA, F.A. Pereira da. Anais pernambucanos. $2^{\mathrm{a}}$ ed. Recife: FUNDARPE, 1984, p. XXII.

52 VALENTE, Waldemar. Maria Graham: uma inglesa em Pernambuco nos começos do século XIX. Recife: Coleção Concórdia, 1957.

${ }^{53}$ VALENTE, Waldemar. Antecipação de Pernambuco no movimento da independência: testemunha de uma inglesa. Recife: Instituto Joaquim Nabuco de Pesquisas Sociais; Conselho Federal de cultura, 1974, p. 71.

54 DELGADO, Luiz. A Convenção de Beberibe. Recife: Comissão Estadual das Comemorações do Sesquicentenário da Independência, 1972, p. 7.

55 LIMA SOBRINHO, Barbosa. Pernambuco: da Independência à Confederação do Equador. $2^{\mathrm{a}}$ ed. Recife: Fundação de Cultura Cidade do Recife, p. 26.

${ }^{56}$ QUINTAS, Amaro. A agitação republicana no Nordeste. In HOLANDA, Sérgio Buarque de. História Geral da civilização brasileira. O Brasil monárquico II. 9a ed. Rio de Janeiro: Bertrand Brasil, 2003, p. 256.

${ }^{57}$ MACHADO, Teobaldo. As insurreições liberais em Goiana. Recife: Fundarpe, 1990.

${ }^{58}$ MACHADO, Teobaldo. As insurreições liberais em Goiana. Recife: Fundarpe, 1990, p. 167.

${ }^{59}$ HABERMAS, Jürgen. Mudança estrutural da esfera pública. Rio de Janeiro: Tempo Brasileiro, 2003.

${ }^{60}$ BALANDIER, Georges. O poder em cena. Brsília: Editora da Universidade de Brasília, 1980.

${ }^{61}$ FARGE, Arlette. Dire et mal dire: l'opinion publique au XVIII siècle. Paris:Seuil, 1992.

${ }^{62}$ BERNARDES, Denis. O patriotismo constitucional: Pernambuco, 1820-1822. São Paulo: Hucitec, 2006, p. 407.

63 BERNARDES, Denis Antônio de Mendonça. Pernambuco e sua área de influência: um território em transformação (1789-1824). In: JANCSÓ, István (org.). Independência: História e historiografia. São Paulo: Hucitec, 2005, p. 379-380.

${ }^{64}$ GRAHAM, Maria. Diário de uma viagem ao Brasil. In: VALENTE, Waldemar. Maria Graham: uma inglesa em Pernambuco nos começos do século XIX. Recife: Imprensa Oficial, 1957, p. 117.

${ }^{65}$ BERBEL, Márcia Regina. A nação como artefato. Deputados do Brasil nas Cortes portuguesas. São Paulo: Hucitec, 1999, p. 110.

${ }^{66}$ CARVALHO, Marcus J.M. de. Cavalcantis e cavalgados: a formação das alianças políticas em Pernambuco, 1817-1824. Revista Brasieira de História, v. 18, n. 36, São Paulo, 1998. Disponível em: <https://www.scielo.br/scielo.php?script=sci_arttext\&pid=S0102-01881998000200014> Acesso em: 28.11.2020.

${ }^{67}$ CARVALHO, Marcus J.M. de. Cavalcantis e cavalgados: a formação das alianças políticas em Pernambuco, 1817-1824. Revista Brasieira de História, v. 18, n. 36, São Paulo, 1998. Disponível em: <https://www.scielo.br/scielo.php?script=sci_arttext\&pid=S0102-01881998000200014> acesso: 28.11.2020. 


\section{Fontes}

Arquivo Nacional (AN)

Fundo Gabinete de D. João VI. BR AN, RIO, U1.0.0.528.

Arquivo Público Estadual Jordão Emerenciano (Apeje)

OC. Cód. 1, fl. 335.

Biblioteca Nacional (BN)

I-35,10,011. "Le roi et la famille royale de Bragança doivent-ils, dans les circonstances présentes, retourner au Portugal, ou bien rester au Brésil?”.

Instituto Arqueológico, Histórico, Geográfico Pernambucano (IAHGP)

Cópias dos ofícios expedidos pelo governo revolucionário [de Goiana], Gaveta 2 - Revolução de 1821.

Registro de ofícios, com as devidas cópias, do governo revolucionário de Goiana, 1821, Coleção Mário Mello, Gaveta 2, Revolução de 1821.

Resumo dos sucessos de Pernambuco, fl. 1v. Coleção Mário Mello, Gaveta 10.

\section{Fontes impressas}

Carta de Luís do Rego para o Ministro Tomás Antônio Vila Nova Portugal, 18 de outubro de 1820. Revista do Instituto Arqueológico, Histórico e Geográfico Pernambucano, p. 156.

Resumo do Tratado celebrado entre este Governo [de Goiana], o Conselho Governativo do Recife - assinado em 6 de outubro de 1821. In: PERNAMBUCO. Pernambuco no movimento da Independência (Correspondência oficial do Governo da Província, entre agosto e outubro de 1821). Recife: Conselho Estadual de Cultura, 1973, p. 144-146.

\section{Jornais}

Relator Verdadeiro, Recife, 10.1.1822.

\section{Bibliografia}

ALEXANDRE, Valentim. Os sentidos do império: questão nacional e questão colonial na crise do Antigo Regime português. Porto: Edições Aforamento, 1993.

ANDRADE, Manuel Correia de. Movimentos nativistas em Pernambuco. Setembrizada e novembrada. Recife: Universidade Federal, 1971.

ARAGÃO, José. História da Vitória de Santo Antão (1626-1843). 2 ed. Recife: Fiam/Centro de Estudos de História Municipal, 1983.

BALANDIER, Georges. O poder em cena. Brsília: Editora da Universidade de Brasília, 1980. BARRETO, Luiz do Rego. Memória justificativa sobre a conducta do marechal de campo Luiz do Rego Barreto durante o tempo em que foi governador de Pernambuco, e presidente da junta constitucional do governo da mesma província. Lisboa: Typografia de Desiderio Marques Leão, 1822.

BELBEL, Márcia Regina. A nação como artefato: deputados do Brasil nas cortes portuguesas, 1821-1822. São Paulo: Hucitec, 1999. 
BERNARDES, Denis Antônio de Mendonça. Pernambuco e sua área de influência: um território em transformação (1789-1824). In: JANCSÓ, István (org.). Independência: História e historiografia. São Paulo: Hucitec, 2005, p. 379-380.

BERNARDES, Denis Antônio. O patriotismo constitucional: Pernambuco, 1820-1822. São Paulo: Hucitec, 2006.

CABRAL, Flavio José Gomes. Conversas reservadas: "vozes públicas", conflitos políticos e rebeliões em Pernambuco no tempo da Independência do Brasil. Rio de Janeiro: Arquivo Nacional, 2013.

CABRAL, Flavio José Gomes. Instabilidades políticas em Pernambuco no tempo da Independência do Brasil (1817-1822), Anos 90, Porto Alegre, v.7, 2020, p. 1-18 Disponível em: https://doi.org/10.22456/1983-201X.90820, acesso em 12.10.2020.

CABRAL, Flavio José Gomes. Paraíso terreal: a rebelião sebastianista na Serra do Rodeador. Pernambuco, 1820. São Paulo: Annablume, 2004.

CARVALHO, Marcus J. M. de. Cavalcantis e cavalgados: a formação das alianças políticas em Pernambuco, 1817-1824. Revista Brasieira de História, v. 18, n. 36, São Paulo, 1998. Disponível em: <https://www.scielo.br/scielo.php?script=sci_arttext\&pid=S010201881998000200014> Acesso em: 28.11.2020.

CARVALHO, Marcus J. M. de. Negros armados por brancos e suas independências no Nordeste (1817-1848). In: JANCSÓ, István (org.). Independência: História e historiografia. São Paulo: Hucitec, 2005, p. 881-914.

COSTA, F.A. Pereira da. Anais pernambucanos. $2^{\mathrm{a}}$ ed. Recife: FUNDARPE, 1984, v. 8.

COSTA, Hipólito da. Correio Braziliense, ou Armazém Literário. São Paulo: Imprensa Oficial do Estado, 2002, v. XXVI.

COSTA, Hipólito da. Correio Braziliense, ou Armazém Literário. São Paulo: Imprensa Oficial do Estado 2002, v. XXVI.

DELGADO, Luiz. A Convenção de Beberibe. Recife: Comissão Estadual das Comemorações do Sesquicentenário da Independência, 1972.

FARGE, Arlette. Dire et mal dire: l'opinion publique au XVIII' siècle. Paris:Seuil, 1992.

FONSECA, Felipe Mena Calado da. Movimento Revolucionário de Goyanna em 1817(sic). Pernambuco: Typografia Mercantil,1873. Revista do Instituto Archeologico e Geographico Pernambucano, vol. XIII, n. 71-74, 1908, pp. 5-69. Disponível em: Disponível em <http://www.dominiopublico.gov.br/download/texto/jn001347.pdf> Acesso em 28.11.2020 GRAHAM, Maria. Diário de uma viagem ao Brasil. In: VALENTE, Waldemar. Maria Graham: uma inglesa em Pernambuco nos começos do século XIX. Recife: Imprensa Oficial, 1957.

GUIMARÃES, Lúcia Maria Paschoal. Entre a monarquia e a república: a Revolução Pernambucana de 1817 e suas representações no Instituto Histórico e Geográfico Brasileiro. In LESSA, Mônica; FONSECA, Sílvia Carla Pereira de Brito. Entre a monarquia e a república: imprensa, pensamento político e historiografia (1822-1889). Rio de Janeiro: 2008.

HABERMAS, Jürgen. Mudança estrutural da esfera pública. Rio de Janeiro: Tempo Brasileiro, 2003.

LIMA SOBRINHO, Barbosa. Pernambuco: da Independência à Confederação do Equador. $2^{\mathrm{a}}$ ed. Recife: Fundação de Cultura Cidade do Recife, 1998.

LIMA, Manuel de Oliveira. O movimento da Independência: 1821-1822. Belo Horizonte: Itatiaia, 1989.

LUSTOSA, Isabel. O jornalista que imaginou o Brasil: tempo, vida e pensamento de Hipólito da Costa (1774-1823). Campinas: Editora da Unicamp, 2019. 
LUSTOSA, Isabel. Insultos impressos: a guerra dos jornalistas na Independência (18211823). São Paulo: Companhia das Letras, 2000.

LYRA, Maria de Lourdes Viana. A utopia do poderoso império. Rio de Janeiro: Sette Letras, 1994.

MACHADO, Teobaldo. As insurreições liberais em Goiana. Recife: Fundarpe, 1990.

MALEVAL, Isadora Tavares. O Instituto Histórico e Geográfico Brasileiro como preparador da história (1850-1889), História Unisinos, v 24, $\mathrm{n}^{\circ}$ 1, 2020, p. 48. Disponível em: <http://revistas.unisinos.br/index.php/historia/article/view/hist.2020.241.05/60747484>

Acesso em 02.07.2020.

MELLO, Evaldo Cabral de. A outra independência: O federalismo pernambucano de 1817 a 1824. São Paulo: Editora 34, 2004.

MOREL, Marco. Da gazeta tradicional aos jornais de opinião: metamorfose da imprensa periódica no Brasil. In: NEVES, Lúcia Maria Bastos P. das (org.). Livros e impressos. Retratos do setecentos e do oitocentos. Rio de Janeiro: Editora da Uerj, 2009, p. 153-184;

MOREL, Marco; MARIANA, M. de Barros. Palavra, imagem e poder: o surgimento da imprensa no Brasil do século XIX. Rio de Janeiro: DP\&A, 2003.

NEVES, Lúcia Maria Bastos das. Corcundas e constitucionais: a cultura política da Independência (1820-1822). Rio de Janeiro: Revan, 2003.

OLIVEIRA, Cecília Helena de Salles. Independência e revolução: temas da política, da História e da cultura visual, Almanak, n. 25, 2020, p. 1-52. Disponível: <https://periodicos.unifesp.br/index.php/alm/article/view/10509/8065> acesso em 01.07. 2020.

PEREIRA, Nilo. Prefácio. In COSTA, F.A. Pereira da. Anais pernambucanos. $2^{\mathrm{a}}$ ed. Recife: FUNDARPE, 1984.

PIMENTA, João Paulo Pimenta. A independência do Brasil e a experiência hispanoamericana (1808-1822). São Paulo: Hucitec Editora, 2015.

PROENÇA, Maria Cândida. A Independência do Brasil: Relações externas portuguesas, 1081825. Lisboa: Livros Horizontes, 1987.

QUINTAS, Amaro. A agitação republicana no Nordeste. In HOLANDA, Sérgio Buarque de. História Geral da civilização brasileira. O Brasil monárquico. $9^{\mathrm{a}}$ ed. Rio de Janeiro: Bertrand Brasil, 2003, p. 235-269, v, II.

RAFFAELLI, Marcelo. Guerras europeias, revoluções americanas. Europa, Estados Unidos e a independência do Brasil e da América Espanhola. São Paulo: Três Estrelas, 2018.

RODRIGUES, José Honório. Conciliação e reforma no Brasil. $2^{\mathrm{a}}$ ed. Rio de Janeiro: Nova Fronteira, 1982.

SILVA, Antonio de Morais. Bluteau, Rafael. Diccionario da lingua portugueza composto pelo padre D. Rafael Bluteau, reformado, e accrescentado por Antonio de Moraes Silva natural do Rio de Janeiro. 1. ed. Lisboa, Simão Tadeu Ferreira, [1789].

SILVA, J. M. Pereira da. História da fundação do império brasileiro. Rio de Janeiro: B. L. Garnier Editor, 1865.

SORGINE, Juliana. Da colônia às Cortes. A formação da Junta Governativa de Goiana e a crise do Antigo Regime português em Pernambuco (1821). 159f. Dissertação (Mestrado em História Social) - Universidade Federal do Rio de Janeiro/IFCS, 2005.

TOMÁS, Manuel Fernandes. A Revolução de 1820. $2^{\mathrm{a}}$ ed. Lisboa: Editorial Caminho, 1982.

VALENTE, Waldemar. Antecipação de Pernambuco no movimento da independência: testemunha de uma inglesa. Recife: Instituto Joaquim Nabuco de Pesquisas Sociais; Conselho Federal de cultura, 1974. 
VALENTE, Waldemar. Maria Graham: uma inglesa em Pernambuco nos começos do século XIX. Recife: Coleção Concórdia, 1957.

VARGUES, Isabel Nobre. O processo de formação do primeiro movimento liberal: a Revolução de 1820. In: TORGAL, Luís dos Reis; ROQUE, João Lourenço. História de Portugal. O Liberalismo. Lisboa: Editorial Estampa, 1998.

VARNHAGEN, Francisco Adolfo de. História Geral do Brasil. Rio de Janeiro: Casa H. Laemmert, 1857.

VARNHAGEN, Francisco Adolfo de. História da Independência do Brasil até ao reconhecimento pela antiga metrópole, compreendendo, separadamente a dos sucessos ocorridos em algumas províncias até essa data. Rio de Janeiro: IHGB, [1919]. 